
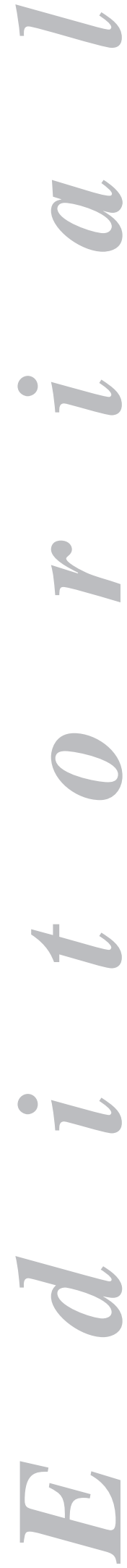

\section{Precut: two (combined techniques) better than one}

One of the most satisfying images for biliary endoscopists is a freely ascending guidewire within the bile duct after struggling (and suffering) to enter the papilla. Such deep biliary cannulation is a necessary prerequisite for elective treatment, usually following sphincterotomy. From the start, this suffering comes by the hand of the endoscopic retrograde cholangio-pancreatography (ERCP) technique. Early endoscopic cannulations of the papilla of Vater by McCune, Shorb, and Moscowitz (1) had a success rate of only $25 \%$. Fortunately enough our performance is now clearly better - improved duodenoscopes, cannulas of various types, sphincterotomes, guidewires and other accessories are available, wherewith different techniques have been developed to access the biliary tract via the pancreatic duct in order to remove stones, drain blocks, repair leaks, or perform a number of other treatments (2-4). However, in spite of these technical and methodological advances we still cannot ensure biliary cannulation on all occasions. Anatomic features and - of courseendoscopist experience play a role in this. It is widely accepted that following appropriate training a biliary endoscopist should be able to cannulate the desired duct in over $80 \%$ of attempts, that most endoscopists should be successful at cannulation in over $85 \%$ of cases, and that expert endoscopists in high-level sites should perform successful cannulations on $95 \%$ of occasions (5). Real practice studies do not fully support these data. A review of over 5,000 ERCPs in England showed that $77 \%$ of endoscopists obtained cannulation rates above $80 \%$, and only $42 \%$ were successful in over $90 \%$ of attempts, not to mention that the cannulation rate among senior endoscopists with more than 200 ERCPs performed was $66 \%$ (too many trainees in too many low-volume centres) (6). A few months ago Revista Española de Enfermedades Digestivas offered a fine article on ERCP implementation in a low-volume hospital (7), as well as a brilliant editorial with contrasting viewpoints on this controversial topic (8).

In summary, despite technological advances, ERCP — most probably the most challenging, complex endoscopic technique with the highest morbidity and mortality - fails to provide the biliary cannulation needed for a complete procedure in up to $20 \%$ of patients $(9,10)$. Alternatives to this failed intervention include referral — when possible - to a more experienced, skilled (or lucky) colleague; delayed examination (another day, other hands), or alternative methods (percutaneous access by interventional radiology, surgery, and more recently — without leaving the endoscopy unit - endoscopic ultrasound-assisted access to the biliary tract $(11,12)$. Another option, possibly before examination delay, would be precut prior to cannulation. So-called precut sphincterotomy —or simply precut_ involves first cutting the duodenal mucosa at the ampulla of Vater in order to uncover the bile duct and facilitate access. 
Early endoscopic precuts were described a few years following the first sphincterotomies reported by Classen and Kawai in 1974, and simply consisted of an extension of existing spontaneous choledocho-duodenal fistulas in the papillary area using the sphincterotome (13). Shortly afterwards a specific endoscopic fistulotomy was performed using a needle-knife sphincterotome in a patient with obstructive jaundice from pancreatic cancer having undergone a failed conventional ERCP procedure (14). The term precut was first used by Siegel in 1980 as a "novel approach to improve success rates in ERCP and sphincterotomy" (15). He used a conventional sphincterotome to advance $3-5 \mathrm{~mm}$ into the papilla and make a cut towards the bile tract. He successfully performed this procedure for 18 patients with scarce complications ( 2 patients with transient fever and high amylase levels). Even then the author concluded "Precut papillotomy is recommended when bile duct opacification is not possible because of papillary stenosis, stone impaction, or natural or acquired anatomic variations, and should only be performed by endoscopists experienced in ERCP and papillotomy" (few changes have occurred over the last 30 years!).

Basically, we may categorize precut methods according to type of sphincterotome (needle-knife sphincterotome and classic or modified pull-type sphincterotome) and cutting technique. Traditionally in needle-knife precut sphincterotomy (NK-PCS) the cutting starts at the papillary orifice itself and proceeds cephalad (towards " 11 o'clock") for at least 5-6 mm at a depth of at least 2-4 mm. Such is the description in the first study representative of the technique by Kees Huibregtse in Amsterdam (16). He used precut for 190 patients and was successful in $91 \%$ of cases with few complications ( $1 \%$ pancreatitis, $1.5 \%$ bleeding), not more than with conventional sphincterotomy. Subsequent studies by this team reveal similar results ( $99 \%$ of success) albeit with more complications (12\%) (17). A variant of this technique also uses a needle-knife sphincterotome to start cutting at the papillary impression and then proceed downwards. This would be needle-knife precut sphincterotomy, fistulotomy type (NK-PCS/F). Advantages include avoidance of the papillary orifice (pancreatitis theoretically less likely) and perhaps clearer anatomic borders. This procedure is preferred by some experts $(18,19)$.

The other group is standard precut sphincterotomy (PCS) or Erlangen-type precut sphincterotomy (ET-PCS), with the Erlangen type being a modified pull-type sphincterotome with a short $(5-10 \mathrm{~mm})$ cutting wire that virtually reaches the instrument's end (leaving a free tip of only 1-2 mm). The use of ET-PCS is limited even though the results achieved by Nib Sohendra's team in Hamburg are very good (20), including as an alternative to conventional cannulation (21). A variant of these precut modalities is performed with a standard sphincterotome by placing its tip (5-6 mm in contrast to the Erlangen variety) within the pancreatic duct and directing the diathermy wire towards " 1 o'clock" to cut the common septum. This is called transpancreatic precut (TPPC) or transpancreatic septotomy, which was initially described by Goffe and has become increasingly popular in the last few years (23-25), possibly because it offers a steadier, better controlled cut versus NK-PCS ("hands-free").

Excellent reviews are available with in-depth technical descriptions and results for precut sphincterotomy $(2,18)$. Its use by endoscopists is highly variable $(0-38 \%)$, initial success in accessing the biliary tract also offers a wide range of results, around $35-97 \%$ (usually above $60-70 \%$ ), and successful outcome rates are usually higher than $90 \%$, with $2-39 \%$ of complications (2). This is one of the big dilemmas and black legends regarding precut. Different multicenter prospective studies show that precut is overall a risk factor for ERCP complications when using a multivariate analysis (26-29). The association of precut with specific complications, particularly 
pancreatitis, yields conflicting results - from studies demonstrating that this procedure indeed is a risk factor in multivariate analyses $(26,28)$ to studies that only show this in univariate analyses (30), through studies where precut is no risk factor at all for pancreatitis $(27,29,31,32)$. Other complications (bleeding, perforation) also show conflicting results in association with precut (33). The overall trend is that most multicenter studies suggest an increase in complications when using precut as compared to conventional sphincterotomy, whereas other studies by experts, usually from tertiary institutions, do not support this notion. Such discrepancies likely reflect different patient profiles, precut timings, techniques, and endoscopist experiences $(34,35)$. As regards precut timing, studies are available that support repeat cannulation attempts (over 10?) with the mechanical and maybe pressure trauma entailed by (unnoticed) injections in the pancreatic duct, and which are more responsible for post-ERCP pancreatitis than precut itself, which might even represent a protective factor when performed early during the procedure (36-38).

No confirmed evidence exists on the superiority of any individual precut technique. When reviewing some of the last-decade studies with higher numbers of patients on the most common precut types, results regarding final success/complications are 70-98\% / 12-15\% for NK-PCS $(37,39,40), 87-90 \% / 5-7 \%$ for NK-PCS/F $(41,42)$, and $56-95 \% / 10-12 \%$ for TPPC $(24,25,40)$.

Few studies compare these techniques with one another, and they usually include few patients. Some suggest similar effectiveness for NK-PCS/F and NK-PCS, with fewer pancreatitis cases with the former modality $(39,43)$. TPPC has gradually consolidated itself as a valid alternative to NK-PCS (44), achieving even better outcomes and fewer complications in some papers (45) while others reveal similar success and complication rates (46). A recent study in 274 patients compared various techniques (NK-PCS $47 \%$, NK-PCS/F 28.5\%, and TPPC 24.5\%). Success rates for these three types of precut were similar but complications were less common with NK-PCS/F (47). In the series with the highest number of TPPCs $(n=262)(40)$ it is concluded that the technique has a high success rate although biliary cannulation is only achieved for $56 \%$ of patients, and $41 \%$ required a subsequent NK-PCS to complete the procedure. An interesting study applied different precut techniques according to the papilla's anatomic features (TPPC for small papillas, NK-PCS for big papillas, and NK-PCS/F for swollen papillas) with positive results (48). Few studies use precut modalities in combination, and those that do so - except for one of the above-mentioned studies (40) — include very few, marginally discussed patients $(26,44,46,48)$.

This issue of Revista Española de Enfermedades Digestivas includes two studies $(49,50)$ on the use of combined precut techniques by the two most experienced Spanish endoscopists in this aspect of ERCP (51-53). Both highlight the benefits of combining various precut modalities to achieve biliary cannulation when a single technique fails to do so.

The review by Espinel (49) of his series (2004-2012) of 247 precuts shows 48 patients with failed TPPC followed by a highly successful NK-PCS, which resulted in biliary cannulation ( $83.3 \%$ at initial endoscopy, $16.6 \%$ required a second procedure) with very few complications - only 1 pt. $(2 \%)$ had bleeding-. Bearing in mind that the combination group included patients whose papilla had undergone at least 5 conventional cannulation, pancreatic cannulation with septotomy, and ultimately needle-knife sphincterotomy attempts, this complication rate is really low, even when compared to separate TPPC and NK-PCS procedures in this same series (9\% and 7\% overall, respectively). Surely the endoscopist's great experience plays a role in these numbers, but we should possibly be cautious in extrapolating these results to other scenarios. 
The study by De la Morena (50) reviewing 119 precuts (2007-2012) shows a group of 20 patients with a failed initial precut where an additional technique was successful in $75 \%$ of cases, thus increasing the combined success rate to $80 \%$ with single precuts and $92 \%$ with combined techniques. In contrast with the previous study combined techniques included both TPPC followed by NK-PCS (14 patients) and NK-PCS followed by TPPC (6 patients), with a success rate of $71 \%$ and $83 \%$, respectively. Increased success in both groups was 70 to $90 \%$ (TPPC + NK-PCS) and 87 to $94 \%$ (NK - PCS + TPPC). An overall complication rate of $18 \%$ is reported (4 pancreatitides, 9 bleeding events, 4 perforations) for all precuts, although with nearly $20 \%$ of failed follow-ups (possibly an underestimation, the author reports). Combine procedures added $17 \%$ of complications (1 bleeding, 2 perforations). While low numbers make it difficult to draw conclusions, the author suggests that, although TPPC + NK-PCS seemed more effective (success increased by 20 versus $7 \%$ for NK-PCS + TPPC), it is NK-PCS + TPPC that he recommends for higher efficacy ( $83 \%$, possibly because of greater biliary cannulation with initial NK-PCS) and safety (added TPPC resulted in only 1 bleeding episode, whereas added NK-PCS gave rise to 2 perforations).

Even though both authors find increased biliary cannulation with combined techniques, differences in success and morbidity rates between these two studies are remarkable: $100 \%$ and $2 \%$ in the study by Espinel versus $75 \%$ and $17 \%$ in the study by De la Morena. Establishing the causes for these differences is indeed challenging. Both authors are renowned for their experience as biliary endoscopists, both series used an ERBE ICC-200 generator with endocut mode on (120 W/effect 2 in the León study, 80 W/effect 3 (TPPC) and 40 W/effect 2 (NK-PCS) in the Madrid study). NK-PCS was also performed by both authors in the classical way (needle at the papillary orifice, cephalad cut), as was TPPC using a standard pull-type sphincterotome (pancreatic duct confirmation with guidewire or contrast in the study by De la Morena, with the guidewire in place during the cutting; the other study only reports the placing of the sphincterotome's tip within the pancreatic duct). Probably, as is the case with other discrepancies, further studies with homogeneous groups of patients in adequate numbers (multicenter studies?) will be needed to confirm the benefits of combined techniques (such is the suggestion of common sense), assess the best scheme, and consider added morbidity.

Interestingly, both studies used no pancreatitis prevention method. Assuming that precut is considered a risk factor for complications in several multicenter studies - even though its association with pancreatitis is more contestable, as discussed above- the fact that not only in these two papers but also in many other precut studies no preventive method is used is outstanding; also, they do use such method when attempting to implant pancreatic stents, usually in small numbers (25,37,40,45-47), although Espinel used such prostheses in $78 \%$ of procedures in his prior study on NK-PCS (52). The European Society for Gastrointestinal Endoscopy (ESGE), in their review in post-ERCP pancreatitis prevention (54), acknowledged that repeat cannulation is a risk factor with greater relevance than precut, regarding which they stated that only experienced endoscopists should perform it, and that its use, timing and technique should be based on anatomic features, personal preference, and indication (grade $\mathrm{C}$ recommendation); furthermore, they specifically mentioned the use of pancreatic stents and rectal NSAIDs as preventive methods with a high grade of evidence (grade A recommendation). It is interesting that, as far as we know, no precut studies report on NSAID use, a cheap, easy-to-administer, effective method likely to provide additional protection for pancreatic stents; a recent cost analysis study suggests that these drugs might even replace them (this assumption remains to be demonstrated) (55). 
In summary, to conclude, combined precut procedures are surely useful to increase ERCP completion rates, but time and further studies are needed to confirm which combinations are more effective and safer, and whether complications derived from such combinations are acceptable, maybe with the use of preventive measures. Anyway, we shall keep the basic rules that have guided the use of precut virtually from its start: stringent indication (exams with therapeutic indication), necessary experience (precut is no substitute for cannulation skills), knowledge of papillary anatomy (each papilla will likely require a specific precut, at least initially), and knowing when to stop (other hands, another day, other technical alternatives).

\section{Juan Ángel González-Martín \\ Department of Gastroenterology. Hospital Universitario Ramón y Cajal. Madrid, Spain}

\section{REFERENCES}

1. McCune WS, Shorb PE, Moscowitz H. Endoscopic cannulation of the ampulla of Vater: A preliminary report. Ann Sug 1968;167:752-6.

2. Freeman ML, Guda NM. ERCP cannulation: A review of reported techniques. Gastrointest Endosc 2005;61:112-25.

3. Qayed E, Reid AL, Willingham FF, Keilin S, Cai Q. Advances in endoscopic retrograde cholangiopancreatography cannulation. World J Gastrointest Endosc 2010;2:130-7.

4. García-Cano J, González-Martín JA. Bile duct cannulation: Success rates for various ERCP techniques and devices at a single institution. Acta Gastroenterol Belg 2006;69:261-7.

5. Baron TH, Petersen BT, Mergener K, Chak A, Cohen J, Deal SE, et al. Quality indicators for endoscopic retrograde cholangiopancreatography. Am J Gastroenterol 2006; 101:892-7.

6. Williams EJ, Taylor S, Fairclough P, Hamlyn A, Logan RF, Martin D, et al. Are we meeting the standards set for endoscopy? Results of a large-scale prospective survey of endoscopic retrograde cholangio-pancreatograph practice. Gut 2007;56:821-9.

7. Riesco López JM, Vázquez-Romero M, Rizo-Pascual JM, Rivero-Fernández M, Manzano-Fernández R, González-Alonso R, et al. Efficacy and safety of ERCP in a low-volume hospital. Rev Esp Enferm Dig 2013;105:68-73.

8. López Roses L, Rodríguez Muñoz S, Vázquez-Sequeiros E, Domínguez Muñoz JE. ERCP in a low volume hospital. Arguments "for" and "against" this type of practice. Rev Esp Enferm Dig 2013;105:61-7.

9. Bourke MJ, Costamagna G, Freeman ML. Biliary cannulation during endoscopic retrograde cholangiopancreatography: core technique and recent innovations. Endoscopy 2009;41:612-7.

10. Larkin CJ, Huibregtse K. Precut sphincterotomy: Indications, pitfalls, and complications. Curr Gastroenterol Rep 2001;3:147-53.

11. Vila JJ, Pérez-Miranda M, Vázquez-Sequeiros E, Abadia MA, Pérez-Millán A, González-Huix F, et al. Initial experience with EUS-guided cholangiopancreatography for biliary and pancreatic duct drainage: A Spanish national survey. Gastrointest Endosc 2012;76:1133-41.

12. Kahaleh M, Artifon EL, Perez-Miranda M, Gupta K, Itoi T, Binmoeller KF, et al. Endoscopic ultrasonography guided biliary drainage: Summary of consortium meeting, May 7th, 2011, Chicago. World J Gastroenterol 2013;19:1372-9.

13. Osnes M, Kahrs T. Endoscopic choledochoduodenostomy for choledocholithiasis through choledochoduodenal fistula. Endoscopy 1977;9:162-5.

14. Caletti GC, Vandelli A, Bolondi L, Fontana G, Labò G. Endoscopic retrograde cholangiography through artificial endoscopic choledochoduodenal fistula. Endoscopy 1978;10:203-6.

15. Siegel JH. Precut papillotomy - a method to improve the success of ERCP and papillotomy. Endoscopy 1980;12:1303.

16. Huibregtse K, Katon RM, Tytgat GNJ. Precut papillotomy via the needle knife papillotome - A safe and effective technique. Gastrointest Endosc 1986;32:403-5.

17. Bruins Slot W, Schoeman MN, Disario JA, Wolters F, Tytgat GN, Huibregtse K. Needle-knife sphincterotomy as a precut procedure: A retrospective evaluation of efficacy and complications. Endoscopy 1996;28:334-9.

18. Sriram PV, Rao GV, Reddy DN. The precut When, where and how? A review. Endoscopy 2003;35:24-30.

19. Coelho-Prabhu N, Dzeletovic I, Baron TH. Outcome of access sphincterotomy using a needle knife converted from a standard biliary sphincterotome. Endoscopy 2012;44:711-4.

20. Binmoeller KF, Seifert H, Gerke H, Seitz U, Portis M, Soehendra N. Papillary roof incision using the Erlangentype pre-cut papillotome to achieve selective bile duct cannulation. Gastrointest Endosc 1996;44:689-95.

21. de Weerth A, Seitz U, Zhong Y, Groth S, Omar S, Papageorgiou C, et al. Primary precutting vs. conventional over-the-wire sphincterotomy for bile duct access: a prospective randomized study. Endoscopy 2006;38: 1235-40. 
22. Goff JS. Common bile duct precut sphincterotomy - Transpancreatic sphincter approach. Gastrointest Endosc 1995;45:502-5.

23. Goff JS. Long-term experience with the transpancreatic sphincter precut approach to biliary sphincterotomy. Gastrointest Endosc 1999;50:642-5.

24. Akashi R, Kiyozumi T, Jinnouchi K, Yoshida M, Adachi Y, Sagara K. Pancreatic sphincter precutting to gain selective access to the common bile duct: A series of 172 patients. Endoscopy 2004;36:405-10.

25. Kahaleh M, Tokar J, Mullick T, Bickston SJ, Yeaton P. Prospective evaluation of pancreatic sphincterotomy as a precut technique for biliary cannulation. Clin Gastroenterol Hepatol 2004;2:971-7.

26. Freeman ML, Nelson DB, Sherman S, Haber GB, Herman ME, Dorsher PJ, et al. Complications of endoscopic biliary sphincterotomy. N Engl J Med 1996;335:909-18.

27. Loperfido S, Angelini G, Benedetti G, Chilovi F, Costan F, De Berardinis F, et al. Major early complications from diagnostic and therapeutic ERCP: A prospective multicenter study. Gastrointest Endosc 1998;48:1-10.

28. Masci E, Toti G, Mariani A, Curioni S, Lomazzi A, Dinelli M, et al. Complications of diagnostic and therapeutic ERCP: a prospective multicenter study. Am J Gastroenterol 2001;96:417-23.

29. Williams EJ, Taylor S, Fairclough P, Hamlyn A, Logan RF, Martin D, et al. Risk factors for complication following ERCP; results of a large-scale, prospective multicenter study. Endoscopy 2007;9:793-801.

30. Freeman ML, Disario JA, Nelson DB, Fennerty MB, Lee JG, Bjorkman DJ, et al. Risk factors for post-ERCP pancreatitis: A prospective, multicenter study. Gastrointest Endosc 2001;54:425-34.

31. Cheng CL, Sherman S, Watkins JL, Barnett J, Freeman M, Geenen J, et al. Risk factors for post-ERCP pancreatitis: A prospective multicenter study. Am J Gastroenterol 2006;101:139-47.

32. Cotton PB, Garrow D, Gallagher J, Romagnuolo J. Risk factors for complications after ERCP: A multivariate analysis of 11,497 procedures over 12 years. Gastrointest Endosc 2009;70:80-8.

33. ASGE GUIDELINE: Complications of ERCP. Gastrointest Endosc 2012;75:467-73.

34. Freeman ML, Guda NM. Prevention of post-ERCP pancreatitis: A comprehensive review. Gastrointest Endosc 2004;59:845-64.

35. Guda NM, Freman ML. 30 years of ERCP and still the same problems? Endoscopy 2007;39:833-5.

36. Manes G, Di Giorgio P, Repici A, Macarri G, Ardizzone S, Porro GB. An analysis of the factors associated with the development of complications in patients undergoing precut sphincterotomy: A prospective, controlled, randomized, multicenter study. Am J Gastroenterol 2009;104:2412-7.

37. Bailey AA, Bourke MJ, Kaffes AJ, Byth K, Lee EY, Williams SJ. Needle-knife sphincterotomy: Factors predicting its use and the relationship with post-ERCP pancreatitis. Gastrointest Endosc 2010;71:266-71.

38. Testoni PA, Mariani A, Giussani A, Vailati C, Masci E, Macarri G, et al. Risk factors for post-ERCP pancreatitis in high- and low-volume centers and among expert and non-expert operators: a prospective multicenter study. Am J Gastroenterol 2010;105:1753-61.

39. Abu-Hamda EM, Baron TH, Simmons DT, Petersen BT. A retrospective comparison of outcomes using three different precut needle knife techniques for biliary cannulation. J Clin Gastroenterol 2005;39:717-21.

40. Halttunen J, Keranen I, Udd M, Kylanpaa L. Pancreatic sphincterotomy versus needle knife precut in difficult biliary cannulation. Sug Endosc 2009;23:745-9.

41. Robison LS, Varadarajulu S, Wilcox CM. Safety and success of precut biliary sphincterotomy: Is it linked to experience or expertise? World J Gastroenterol 2007;13:2183-6.

42. Donnellan F, Zeb F, Courtney G, Aftab AR. Suprapapillary needleknife fistulotomy: A safe and effective method for accessing the biliary system. Surg Endosc 2010;24:1937-40.

43. Mavrogiannis C, Liatsos C, Romanos A, Petoumenos C, Nakos A, Karvountzis G. Needle-knife fistulotomy versus needle-knife precut papillotomy for the treatment of common bile duct stones. Gastrointest Endosc 1999;50:334-9.

44. Kapetanos D, Kokozidis G, Christodoulou D, Mistakidis K, Dimakopoulos K, Katodritou E, et al. Case series of transpancreatic septotomy as precutting technique for difficult bile duct cannulation. Endoscopy 2007;39:802-6.

45. Catalano MF, Linder JD, Geenen JE. Endoscopic transpancreatic papillary septotomy for inaccessible obstructed bile ducts: comparison with standard pre-cut papillotomy. Gastrointest Endosc 2004;60:557-61.

46. Chan CH, Brennan FN, Zimmerman MJ, Ormonde DG, Raftopoulos SC, Yusoff IF. Wire assisted transpancreatic septotomy, needle knife precut or both for difficult biliary access. J Gastroenterol Hepatol 2012;27:1293-7.

47. Katsinelos P, Gkagkalis S, Chatzmavoudis G, Beltsis A, Terzoudis S, Zavos C, et al. Comparison of three types of precut technique to achieve common bile duct cannulation: a retrospective analysis of 274 cases. Dig Dis Sci 2012;57:3286-92.

48. Horiuchi A, Nakayama Y, Kajiyama M, Tanaka N. Effect of precut sphincterotomy on biliary cannulation based on the characteristics of the major duodenal papilla. Clin Gastroenterol Hepatol 2007;5:1113.

49. Espinel-Díez J, Pinedo-Ramos E, Vaquero-Ayala L, Álvarez-Cuenllas B, Ojeda-Marrero V. Combined precut in difficult biliary cannulation. Rev Esp Enferm Dig 2013;105:334-7.

50. De la Morena Madrigal E. Impact of combined precut techniques on selective biliary cannulation. Rev Esp Enferm Dig 2013;105:338-44.

51. De la Morena EJ, Domínguez M, Lumbreras M, Opio V, Moyano E, García Álvarez J. Self-training in needleknife sphincterotomy. Gastroenterol Hepatol 2000;23:109-15.

52. Espinel Díez J, Vivas Alegre S, Muñoz Núñez F, Domínguez Carbajo A, Villanueva Pavón R, Jorquera Plaza F, et al. Esfinterotomía de aguja como técnica de acceso a la vía biliar: estudio prospectivo. Gastroenterol Hepatol 2005;28:369-74.

53. Espinel-Díez J. Acceso a la vía biliar mediante esfinterotomía transpancreática. Gastroenterol Hepatol 2006;29:281-5.

54. Dumonceau JM, Andriulli A, Deviere J, Mariani A, Rigaux J, Baron TH, et al. European Society of Gastrointestinal Endoscopy (ESGE) Guideline: prophylaxis of post-ERCP pancreatitis. Endoscopy 2010;42:503-15.

55. Elmunzer BJ, Higgins PD, Saini SD, Scheiman JM, Parker RA, Chak A, et al. Does rectal indomethacin eliminate the need for prophylactic pancreatic stent placement in patients undergoing high-risk ERCP? Post hoc efficacy and cost-benefit analyses using prospective clinical trial data. Am J Gastroenterol 2013;108:410-5. 